\title{
Three-Phase Induction Motor Stator Current Optimization
}

\author{
Rateb H. Issa \\ Mechatronics Engineering Department \\ Faculty of Engineering Technology \\ Al-Balqa Applied University \\ Amman, Jordan
}

\begin{abstract}
This research presents two mathematical -based optimal control systems for induction motor drives leading to stator current optimization and energy saving. The first is a classical optimal control system, which uses information on torque of the motor to generate the appropriate voltage amplitude that minimizes the induction motor stator current. The second is a genetic algorithmbased optimal control system, which uses information on torque of the motor to generate the appropriate minimum stator current according to fitness function.

The constant V/f optimal stator current controller models have been configured and built depending on a set of experimental data using MATLAB computer program, the models were validated by simulation using a typical induction motor drive model implemented with MATLAB/Simulink toolbox.

The aim of this research is the industrial machineries performance improvement by analyzing and designing the induction motor optimal stator current controller, this will minimize the stator current under different loading conditions. Depending on the motor shaft mechanical load torque in order to minimize the stator current, the controller will supply stator of motor with proper voltage and frequency using appropriate control algorithm for industrial machinery.
\end{abstract}

\section{General Terms}

Algorithms, Performance, Experimentation

\section{Keywords}

Induction Motor, Stator Current, Optimization, Modeling, Simulation, Genetic Algorithm.

\section{INTRODUCTION}

Induction motors with squirrel-cage are widely used in industrial environments because of their low cost and rotors rugged construction. With the invention of variable voltage variable frequency drives (VVVF); the use of an induction motor has increased [2].

The induction motor is a simple and robust machine, but its control might be a complex task when managed directly from the line voltage, the motor operates at nearly a constant speed [17]. To obtain speed and torque variations, it is necessary to modify both the voltage and the frequency. Following this was the realization that the ratio of the voltage and frequency should be approximately constant [8] \& [21].

The induction motor has also disadvantages that it has more losses and less efficiency when it works at variable speeds. The need of efficient drive systems was achieved by special controllers that not only modify the losses and efficiency, but also searching for the optimal values of stator current to reduce the power consumption from the source to be minimum [16] \& [19].

The trends of designing optimal controllers was developed due to the increasing in power consumption, which represents the most important problem in the world due to the decreasing in power resources in the last few decades [5] \& [15]. The studies proved that there is a possibility to decrease the power consumption and increase the efficiency in the induction motor.

The control system which achieves all of these conditions is called the drive system optimization [1], [10] \& [25].

The drive system optimization has many advantages which explain the widely use of it, but the application always determines what is wanted from these advantages, so some optimal controllers have been designed to achieve a good speed control principles while the others to increase the accuracy and the efficiency, but the concentration nowadays takes the direction of energy saving. With the technology revolution, the techniques of designing optimal controllers vary as the objectives of these controllers vary [6] \& [13]-[14].

One of the important parameters of induction motor that requires optimization is stator current, this value should be minimized, and to reach that, some technologies were invented and developed, so the methods of optimizing were mathematical, while the others developed with the invention of the Fuzzy Logic and genetic algorithm(searching) Controllers [3]-[4] \& [24].

Many parameters are affected by stator current minimization of induction motors such as, efficiency, power loss and power factor. All these factors must be considered at loads which are less than nominal loads, due to their influence on the whole performance of an induction motor. In other words, these parameters have to be optimized simultaneity by reducing the unnecessary excess currents at light loads, which is normally dissipated as heat through the motor [16].

As a result, the motor runs cooler, quieter and with less vibration and accordingly the motor's life will increase [20].

Motor operation under rated conditions is highly efficient. However, in many applications, a motor operates far from the rated point. Under these circumstances, it is not possible to improve the motor performance by motor design or by supply waveform shaping technique. So, a suitable control algorithm that minimizes the motor current will rather take place [18]. 


\section{BASIC COMPONENTS OF OPEN LOOP AC DRIVE SYSTEM}

The basic components of ac drive system are shown in figure 1.

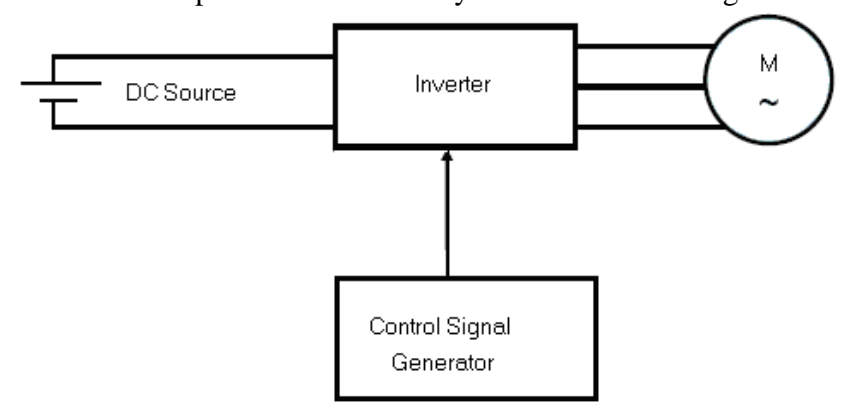

Figure 1 Basic components of open loop ac drive system

The ac drive system consists of:

1. Three Phase squirrel cage Induction Motor

The three-phase squirrel cage induction motor is commonly used in industrial machineries.

The ratings and parameters of three- phase squirrel cage type motor are shown in table 1.

\section{Inverter and control signal generator}

The voltage source inverter is used to invert the dc signal into an ac signal with a variable frequency and a proportionally variable voltage, using the Principle of Constant V/F Ratio. It consists of six electronic switches which are "switched on/off" by PWM control signals in order to create an AC output voltage [1].

It is a well-known fact that the speed of an induction motor depends primarily on the pole number of the motor and the frequency of the voltage supplied. The amplitude of the voltage supplied and the load on the motor shaft also influence the motor speed, however not with the same degree.

Consequently, changing the frequency of the supply voltage is an ideal method for induction motor speed control. In order to ensure a correct motor magnetization, it is also necessary to change the amplitude of the voltage according to the following equations:

The value of active EMF is:

$$
\mathrm{E}=4.44 \Phi_{\max } \mathrm{f} \mathrm{N}
$$

Where:

$$
\begin{aligned}
& E \text { : Electromagnetic Motive Force. } \\
& \mathrm{f}: \text { Supply Frequency. } \\
& \Phi \text { : Flux. } \\
& \mathrm{N}: \text { Stator windings turn number. }
\end{aligned}
$$

Assuming, that the voltage drop of stator circuit is negligible, the relationship between the voltage and the frequency is written as:

$$
\mathrm{V}=\mathrm{K} \phi \mathrm{f}
$$

Where:

$\mathrm{V}:$ Stator Voltage [V].

$\mathrm{K}$ : Constant.
Table 1 Rating parameters of induction motor

\begin{tabular}{|l|l|}
\hline \multicolumn{2}{|c|}{ Induction Motor Parameters } \\
\hline Number of poles & 4 \\
\hline Rated power & $4[\mathrm{~kW}]$ \\
\hline Rated voltage, $\mathrm{V}_{\mathrm{L}-\mathrm{L}}$ & $400[\mathrm{~V}]$ \\
\hline Rated frequency, $\mathrm{f}^{2}$ & $50[\mathrm{~Hz}]$ \\
\hline Stator resistance , $\mathrm{R}_{1}$ & $1.405[\Omega]$ \\
\hline Rotor resistance, $\mathrm{R}_{2}^{\prime}$ & $1.395[\Omega]$ \\
\hline Stator inductance, $\mathrm{L}_{1}$ & $0.005839[\mathrm{H}]$ \\
\hline Rotor inductance, $\mathrm{L}_{2}^{\prime}$ & $0.005839[\mathrm{H}]$ \\
\hline Air gap inductance, $\mathrm{L}_{\mathrm{m}}$ & $0.1722[\mathrm{H}]$ \\
\hline Inertia , J ${ }_{\Sigma}$ & $0.0131\left[\mathrm{~kg} . \mathrm{m}^{2}\right]$ \\
\hline
\end{tabular}

Therefore, in order to maintain the motor flux, the V/F ratio has to be kept constant. This is known as the constant Volt/Hertz principle. This principle is illustrated in Figure 2.

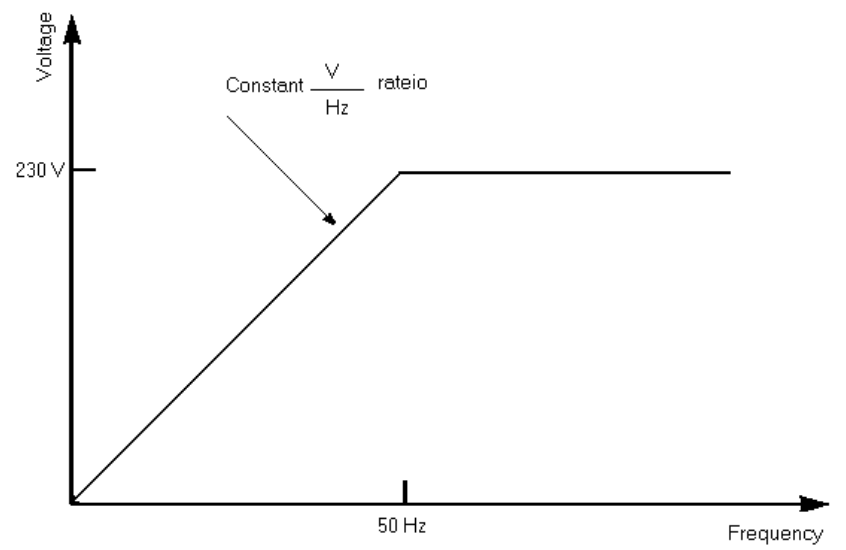

Figure 2 Voltage versus frequency under the constant $\mathrm{V} / \mathrm{Hz}$ principle

The stator voltage values can be varied by varying the modulation index $\left(\mathrm{M}_{\mathrm{a}}\right)$, using the principle of constant V/f ratio [11] \& [22][23].

The study and analysis of modeling and simulation of open loop ac drive system using different approaches showed that, the statespace model and embedded MATLAB model give identical responses under the same operating conditions [21].

In this research the open loop ac drive system components are modeled using embedded MATLAB/ Simulink models. 


\section{OPTIMAL STATOR CURRENT CONTROL SYSTEMS}

The optimal control system is a closed loop system used to drive or control processes and keep the variables in these processes at optimal values in spite of the influences that affect it. The optimal control system is also a programmed controller and has the ability to self-searching for the optimal values of the variables when the changes affect the processes.

The motor stator current optimization can be achieved by using one of the following systems:

1- Classical optimal stator current control system

The classical optimal stator current control system is a closed loop drive system with optimal current controller working at different frequencies using automatic switch.

The classical optimal control system can be implemented on ac drive systems equipped with torque sensor and for which the steady state speed- torque characteristics are known.

\section{2- Adaptive searching optimal stator current control system}

The motor stator current can be optimized by using a new control strategy, which is categorized as global search technique, and is used in computing to find true or optimum stator current for a given load torque.

Adaptive searching control is genetic algorithm-based control, using MATLAB program.

\section{CLASSICAL OPTIMAL STATOR CURRENT CONTROL SYSTEM MODELING}

The classical optimal stator current control system consists of open loop ac drive system and optimal stator current controller, which should be designed and modeled.

\subsection{Design of Optimal Stator Current Controller}

The optimal current values and corresponding voltages at different load torques can be obtained by varying the stator voltage throughout the modulation index variation.

The minimum current points for different load torques were calculated and pointed out on V-I curve of the induction motor, as shown in figure 3 .

The resultant minimum points obtained by fitting V-I curve represent the optimal voltages and the optimal currents values for different load torques at nominal frequency, and satisfy the best performance for motor operation .These values are shown in table 2.

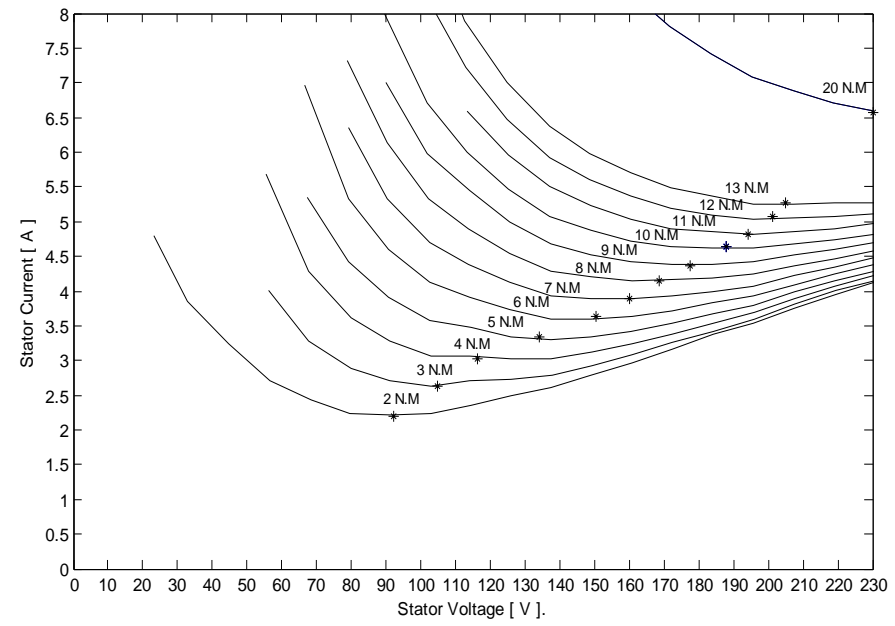

Figure 3 Induction motor V-I curves at different load torques

Table 2 Optimal voltages and currents of variant load torques at nominal frequency

\begin{tabular}{|c|c|c|}
\hline$T_{L}[\mathbf{N . ~ m ]}$ & $V_{o p t}[\mathbf{V}]$ & $I_{o p t}[\mathbf{A}]$ \\
\hline 2 & 92.0591 & 2.1982 \\
\hline 3 & 104.9087 & 2.6392 \\
\hline 4 & 116.4275 & 3.0237 \\
\hline 6 & 150.5038 & 3.6373 \\
\hline 8 & 168.681 & 4.179 \\
\hline 10 & 181.6806 & 4.6372 \\
\hline 12 & 201.736 & 5.0644 \\
\hline 13 & 210.139 & 5.1987 \\
\hline 20 & 230 & 6.578 \\
\hline
\end{tabular}

The relationship between the stator voltage and the stator current at different load torques can be obtained by using MATLAB Curve Fitting Toolbox and data in table 2, as shown in figure 4.

The optimal current controller's equation at nominal frequency is given by:

$\mathrm{V}_{\mathrm{s}}=\mathrm{a}_{1} \mathrm{I}_{\mathrm{s}}^{4}+\mathrm{a}_{2} \mathrm{I}_{\mathrm{s}}^{3}+\mathrm{a}_{3} \mathrm{I}_{\mathrm{s}}^{2}+\mathrm{a}_{4} \mathrm{I}_{\mathrm{s}}+\mathrm{a}_{5}$ 
Where:

$$
\begin{aligned}
& a_{1}=0.34607 ; a_{2}=-7.6161 ; a_{3}=54.94 ; a_{4}=-120.06 \\
& a_{5}=162.58
\end{aligned}
$$

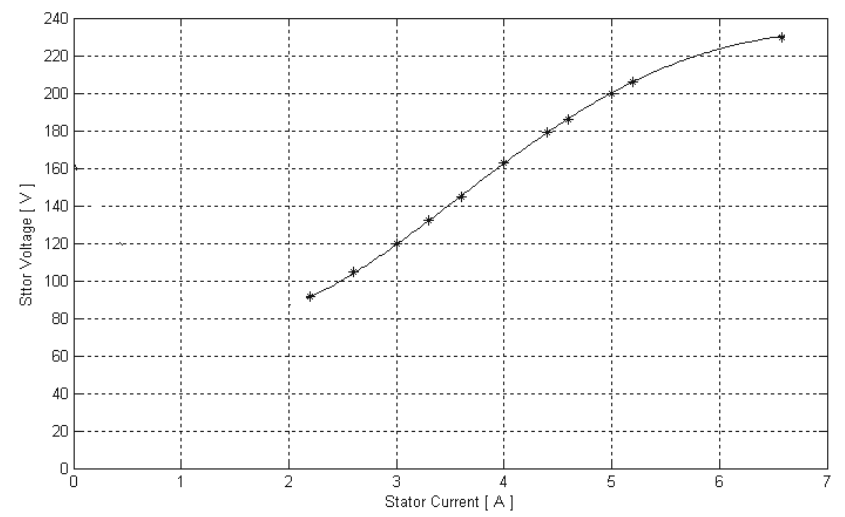

Figure 4 Optimal stator voltage- stator current fitting Curve

\section{2 Modeling of Optimal Stator Current Controller}

Figure 5 shows the model of optimal stator current controller at nominal frequency, built using relationship (3) and MATLAB/ Simulink toolbox.

By following the same technique, different current controllers can be built; each of them can drive the system at certain frequency as shown in figure 6.

According to frequency applied, an automatic switch can select proper controller, which applies the suitable modulation index as a control signal to control the value of applied voltage on the stator.

Automatic switch has four input ports, one port for each controller.

This switch uses control signal (CS) to determine the required input port (suitable controller), the control signal computed by the following relationship:

$$
\mathrm{CS}=-0.1 \mathrm{f}+6
$$

Figure 6 shows the optimal controller model at different frequencies using automatic switch.

The model of classical optimal stator current control system is shown in figure 7 .

\section{GENETIC ALGORITHM-BASED OPTIMAL STATOR CURRENT CONTROL SYSTEM MODELING}

Genetic algorithm is used as a method to search and make an improvement to solve the problem of "how to optimize the current to give a motor an optimal voltage that can be the best value at any load".

Genetic algorithm can be used to automatically determine the optimal values for the variables that optimize the profit, and it is

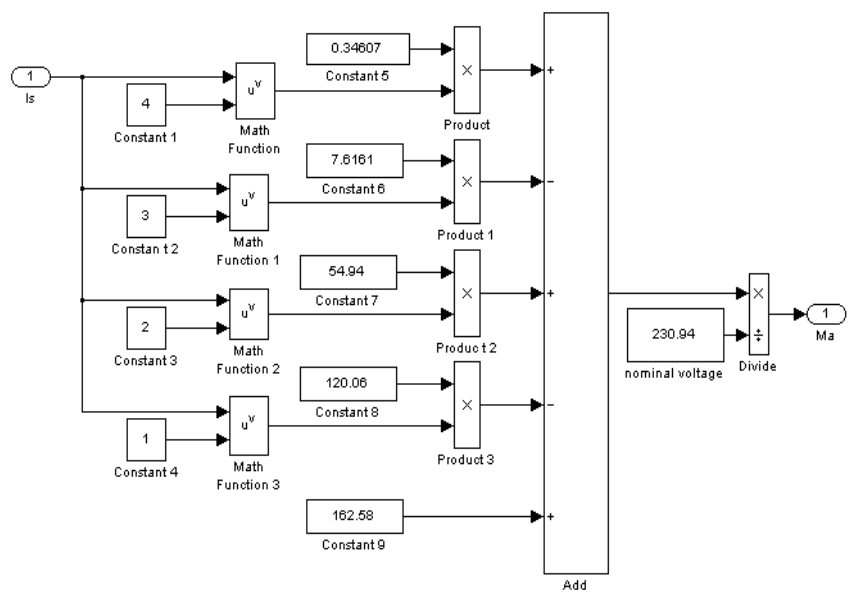

Figure 5 Model of optimal current controller at nominal frequency

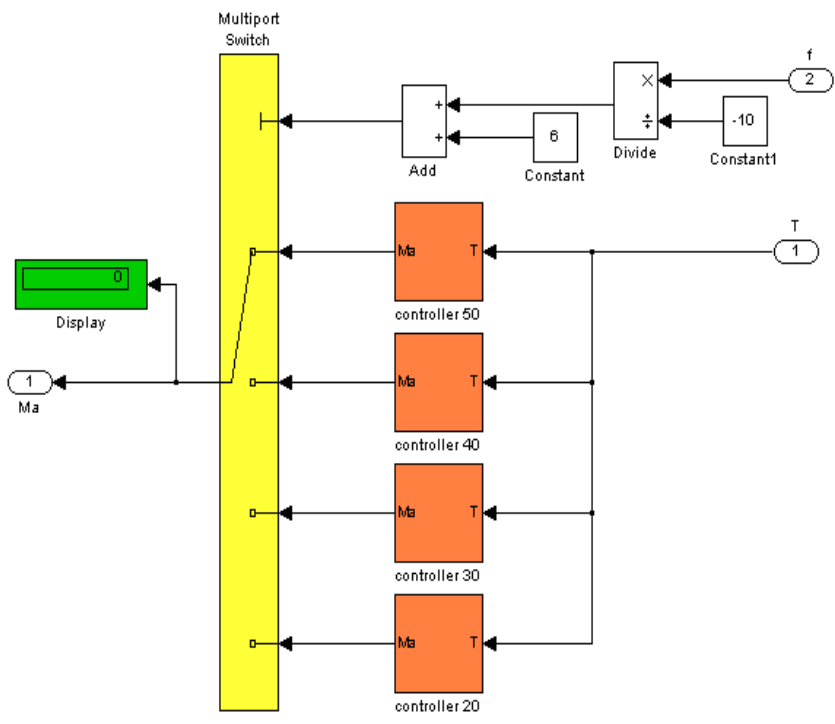

Figure 6 Model of optimal current controller at different frequencies

a search algorithm based on the mechanics of natural genetics. The idea of genetic algorithm is to evolve a population of candidate solutions to a given problem, using operators inspired by natural genetic variation and natural selection [7].

The genetic algorithm repeatedly modifies a population of individual solutions. At each step, the genetic algorithm selects individuals at random from the current population to be parents and uses them for producing the children for the next generation. Over successive generations, the population "evolves" toward an optimal solution [12].

In the most general sense, genetic algorithm-based optimization is stochastic search methods that involves the random generation of potential design solutions and then systematically evaluates and refines the solutions until a stopping criterion [9]. 


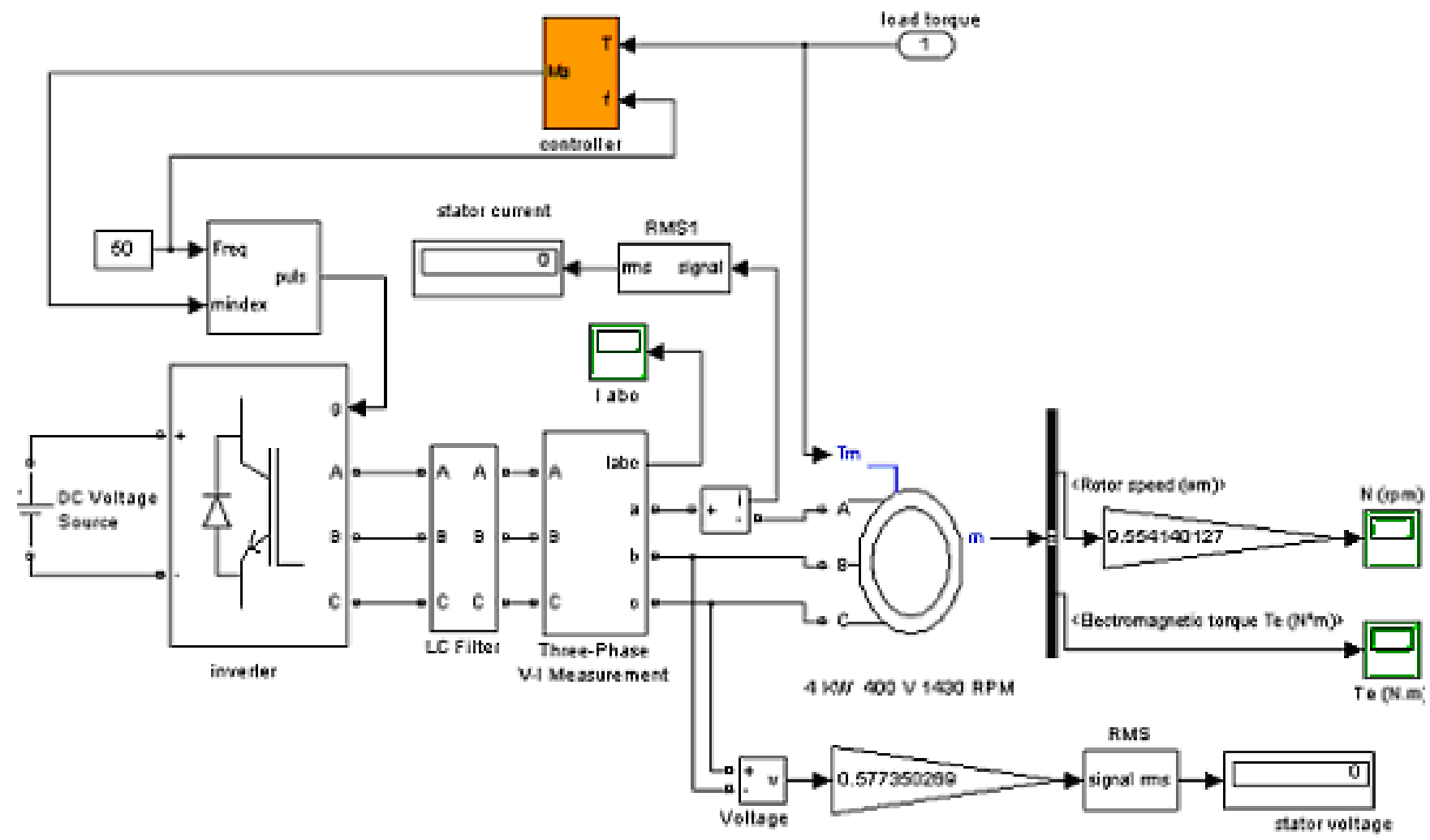

Figure 7 Model of classical optimal stator current control system

The difference between genetic algorithm-based control system and classical control system is:

The genetic algorithm generates a population of points at each of iterations. The best point in the population approaches an optimal solution, and selects the next population randomly. But classical control generates a single point at each of iterations. That needs a sequence of points to approach an optimal solution, and to select the next point in the sequence a deterministic computation is necessary.

\subsection{Design and Modeling of Genetic Algorithm -Based Optimal Stator Current Controller}

The genetic algorithm- based optimal stator current controller flow chart is shown in figure 8 .

The genetic algorithm-based optimal stator current controller flow chart components are modeled using MATLAB toolbox as shown in the following paragraph.

\section{1- Initial Population}

The main operation of this block is passing current to make an initial population by obtaining stator current values randomly. Through depending on the time in every (on/off delay) block, the current value will be hold.
Model of Initial Population is shown in figure 9.

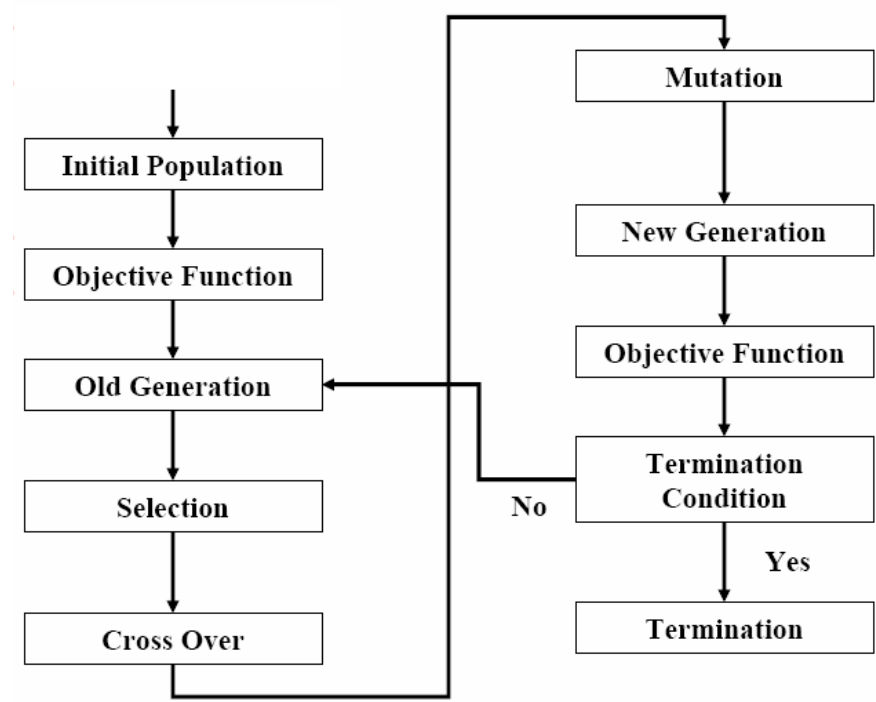

Figure 8 Genetic algorithm- based optimal stator current controller flow chart 


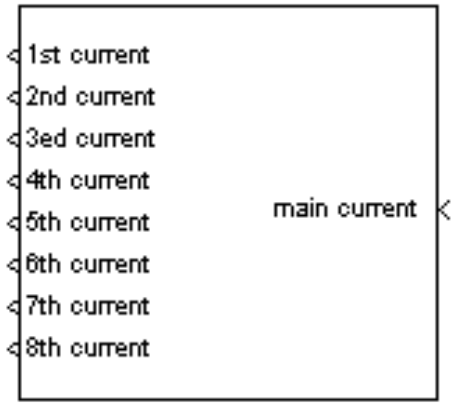

Create Initial popultion

Figure 9 Model of initial population

2- Objective Function (Fitness Function)

The relationship between the load torque and minimum current is used as a fitness function, to describe if any obtained value from initial population, and crossover and mutation is to be used.

As shown in figure 10, the objective function is represented as a lookup table by using the load torque as input and the minimum current as output.

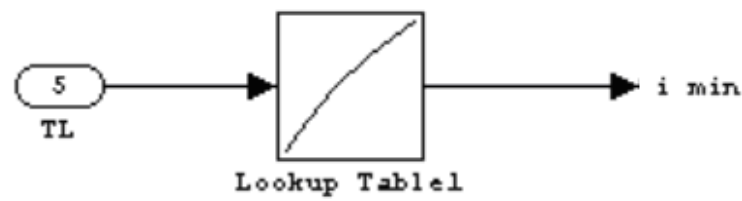

Figure 10 Model of objective function

\section{3- Selection}

To make a good decision, the selection section (as shown in figure 11) calculates the minimum absolute error for the population .If the fitness of any member obtained from the initial population is compared with the fitness function and gives larger error, the member does not survive. However, if it gives smaller error, the member survives and its genes will be out, and may be used in order to create new members in the crossover section.

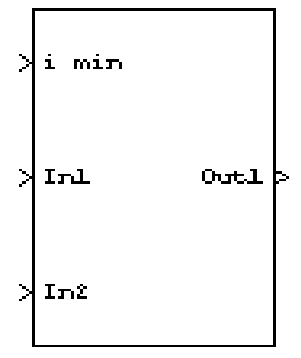

Figure 11 Model of selection

\section{4- Crossover}

Crossover combines two individuals, or parents, to form a new individual, or child, for the next generation. As shown in figure 12, a logical AND operation is used for the input value with a constant binary number, the two blocks (AND, AND2) make a logical AND operation for the input value with (00000011), and the other two blocks (AND1, AND3) make a logical AND operation for the other input value with (11111100), then a logical summation is used for the output of the AND gates by using OR gates (OR, OR1).

0011. $1000 * 0000.0011=0000.0000($ AND operation for block [AND]).

0010. $0010 * 1111.1100=0010.0000($ AND operation for block [AND1]).

000. $0000+0010.0000=0010.0000(\mathrm{OR}$ operation for block $[\mathrm{OR}])$.

The same result is shown on display no.16 $(0010.0000)_{2}$.

The same sequence of logic operations is done for all other input values.

Figure 12 shows the model of crossover.

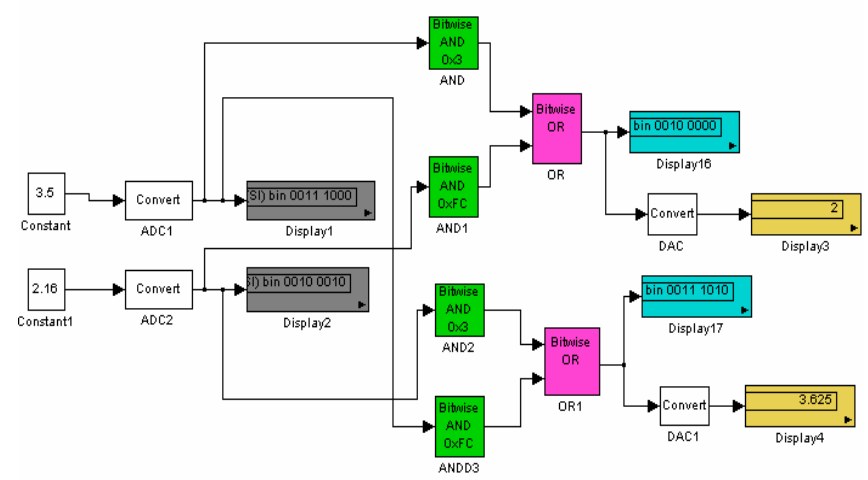

Figure 12 Model of crossover

5- Mutation

Mutation makes small changes in the individuals of the population, which provide genetic diversity and enable the genetic algorithm to search a broader space.

To include this step in simulation, (XOR) logic gate is used to operate as a complement for one bit of the binary string. Figure 13 shows the model of mutation.

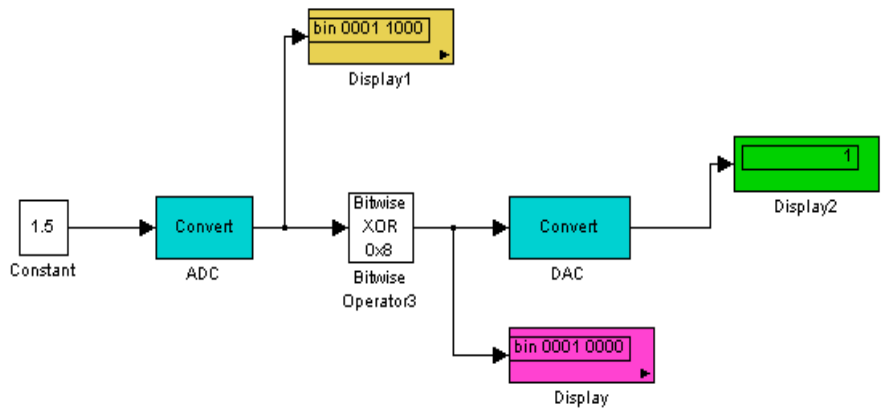

Figure 13 Model of mutation

6- Termination condition (stopping criteria)

The following criteria could be used to terminate the algorithm:

A- Generation- specifies the maximum number of iterations the genetic algorithm performs. 
B- Time limit- specifies the maximum time in seconds the genetic algorithm runs before stopping.

C- Fitness limit - If the best fitness value is less than or equal to the value of fitness limit, the algorithm stops.

In this research the time limit as stopping criteria is used.

Figure 14 shows the model of optimal stator current controller based on genetic algorithm.

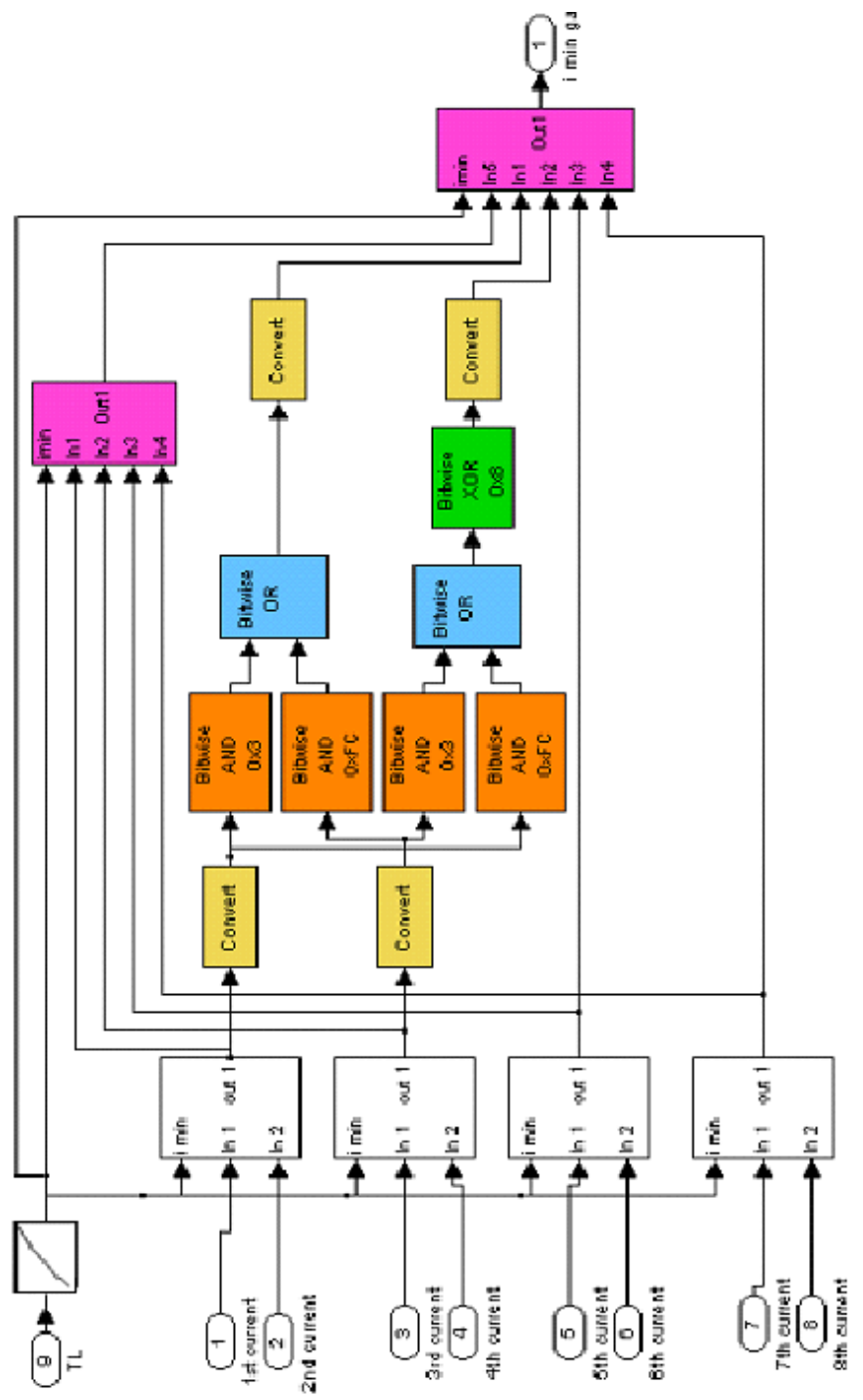

Figure 14 Model of optimal stator current controller based on genetic algorithm

\subsection{Description of Main Algorithm of Genetic Algorithm Model}

As shown in figure 15, in the first stage, after turning the motor on, the shaft load torque is measured and used to generate the appropriate minimum current according to fitness function. The first population of stator current values obtained from the first generation is considered as initial population for the algorithm, hence, to achieve the minimum error between the calculated and measured stator current values, the initial population must be compared with the fitness function. If the state implemented (is yes), the value which will be out is considered the minimum current, (if not) the value enters a crossover process then moves to mutation stage to create a new population, partly mutated and largely crossovers. After that, all offspring (result values of crossover and mutation) make up a new generation, which return to the previous steps and start the process again, and so on.

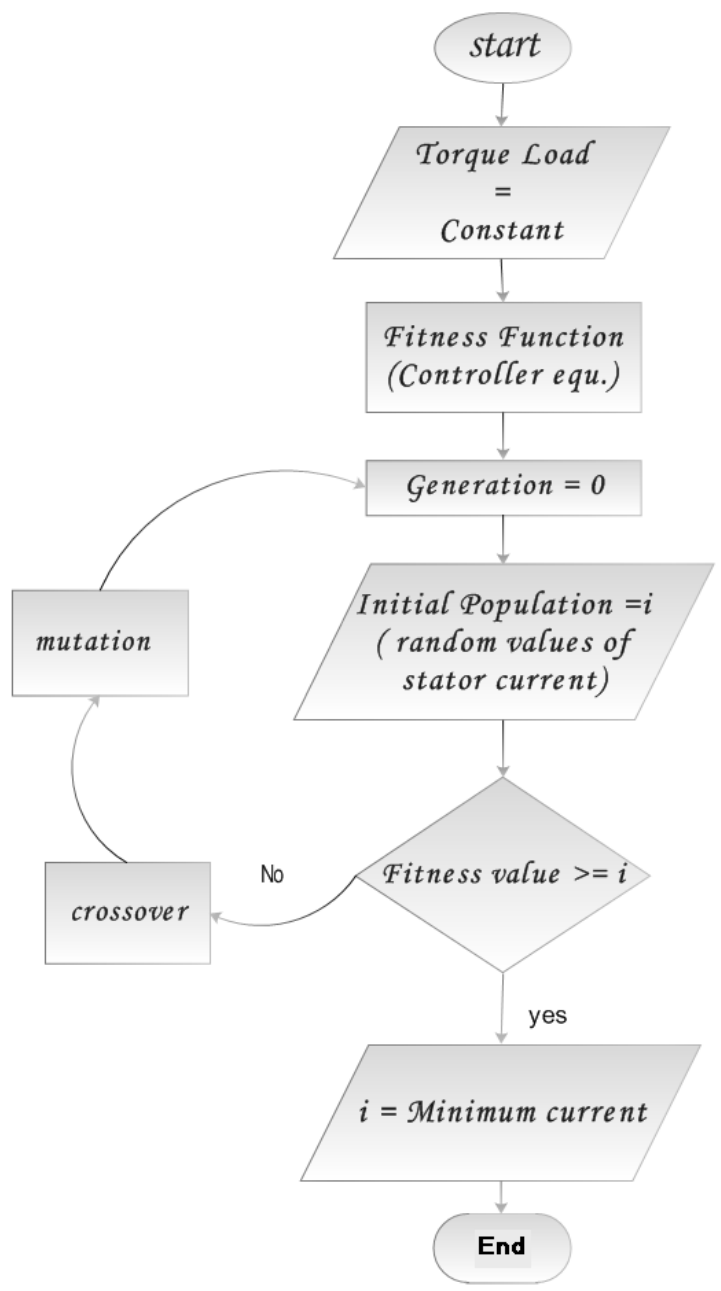

Figure 15 Main algorithm of genetic algorithm model

\subsection{Optimal Stator Current Control System Model Based on Genetic Algorithm}

The model of optimal stator current control system based on genetic algorithm is shown in figure 16 . 


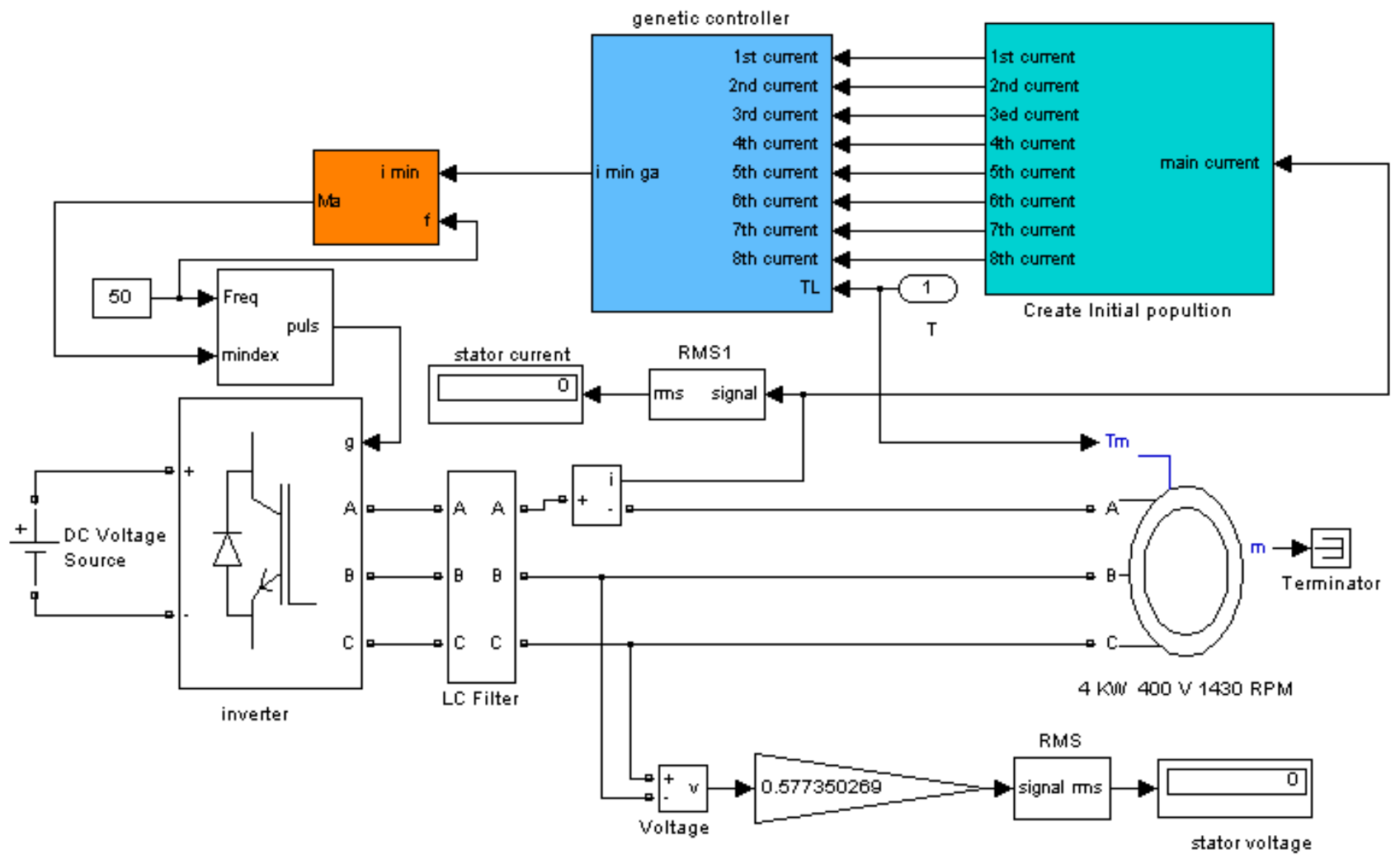

Figure 16 Model of optimal stator current control system based on genetic algorithm

\section{RESULTS AND CONCLUSIONS}

The simulation results of open-loop ac drive system, classical optimal control system and genetic algorithm-based optimal control system are presented. All these results are supported by figures that compare the three above-mentioned systems. These figures show an improvement of stator current minimization, leading to energy saving which is the aim of this research.

The figures (17-19) represent stator current versus load torque relationship at different frequencies for open loop, classical and genetic algorithm-based control systems.

The figures(20-22) show a real- time comparison of steady state stator current at different load torques and different frequencies for open-loop, classical and genetic algorithm-based control systems.

The results show greater stator current minimization, when implementing genetic algorithm-based control system, comparing with classical control system.

As a result, it is obvious that both classical control system and genetic algorithm-based control system provide very good opportunities to save energy reduce operating costs and increase profits.
Using optimal stator current controller in industrial drive systems under different loading conditions will give significant energy saving (reduction of power consumption) by minimizing stator current consumption and minimizing input power consumption.

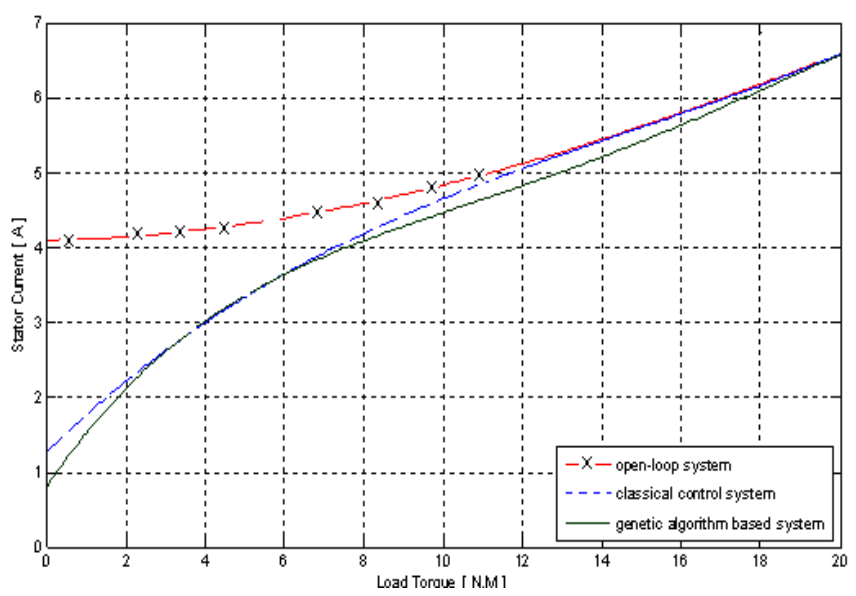

Figure 17 Stator current comparisons at nominal frequency (f $=\mathbf{5 0 H z})$ 


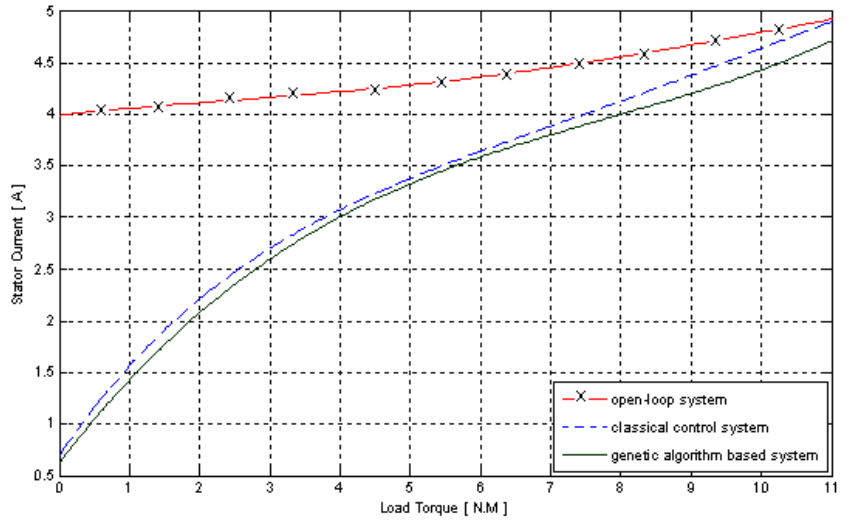

Figure 18 Stator current comparison at frequency $(f=30 \mathrm{~Hz})$

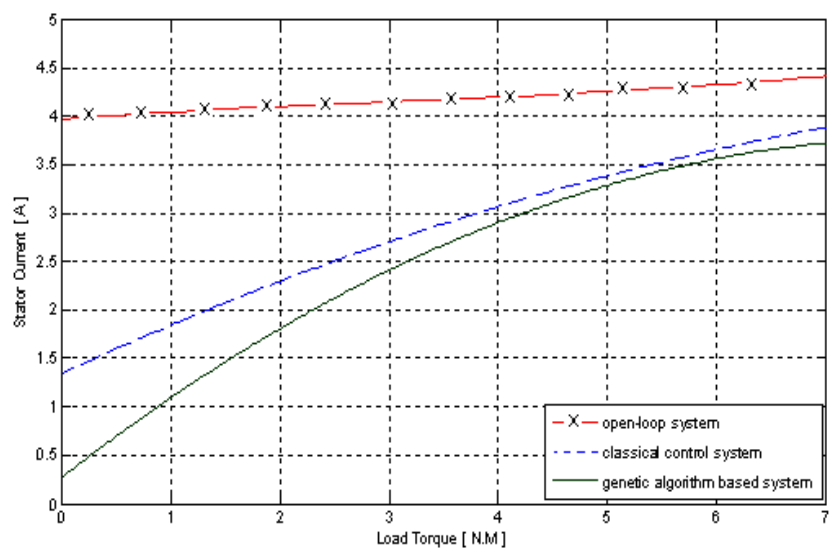

Figure 19 Stator current comparison at frequency $(f=10 \mathrm{~Hz})$

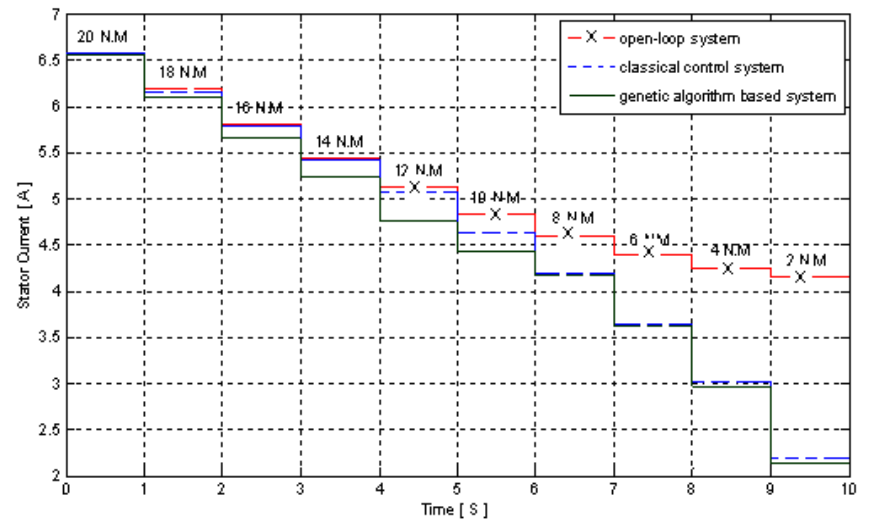

Figure 20 Real-time stator current comparison at different loads at nominal frequency $(\mathrm{f}=50 \mathrm{~Hz})$

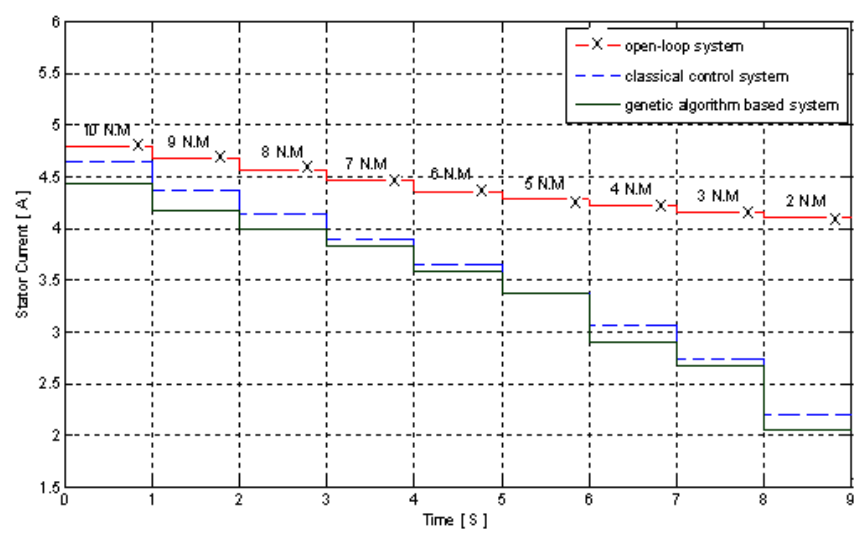

Figure 21 Real-time stator current comparison at different loads at frequency $(\mathrm{f}=30 \mathrm{~Hz})$

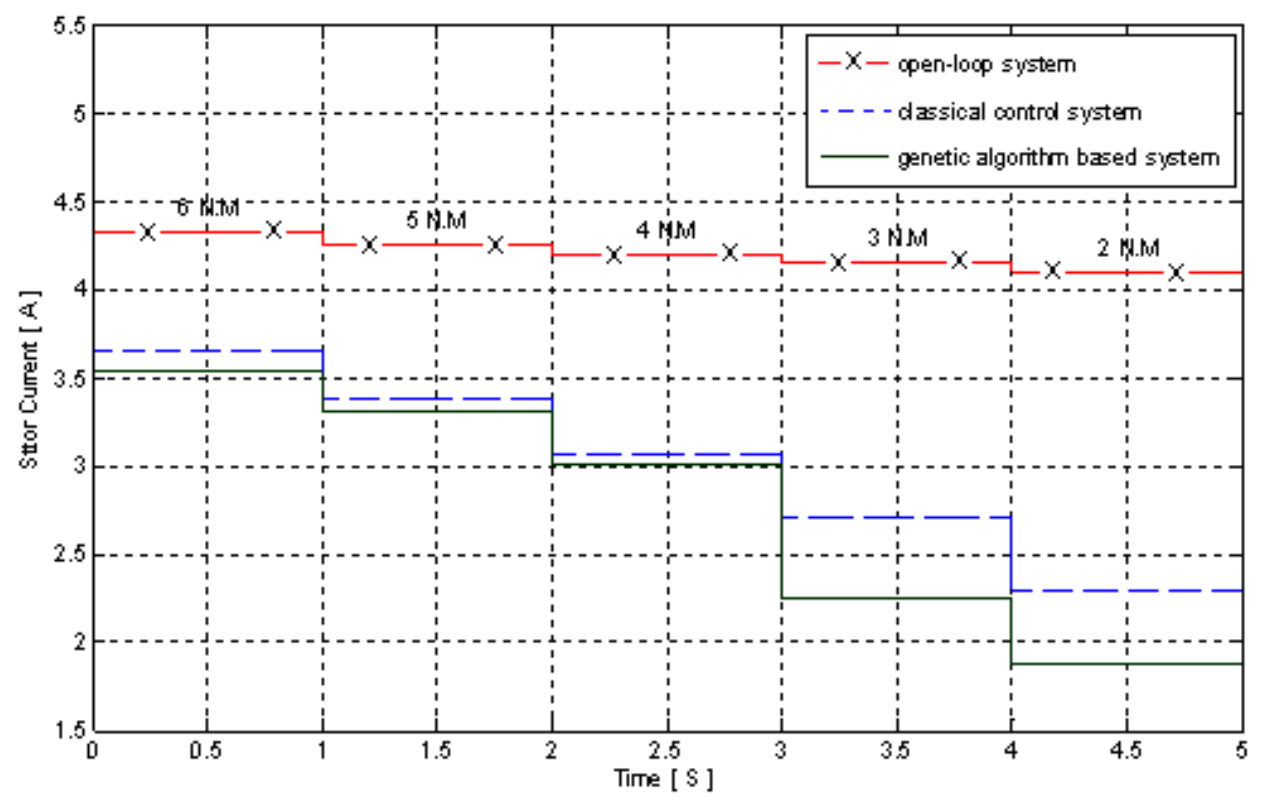

Figure 22 Real-time stator current comparison at different loads at frequency $(f=10 \mathrm{~Hz})$ 


\section{REFERENCES}

[1] Bhim Singh and Singh,B.N. "Experience in the design optimization of a voltage source inverter fed squirrel cage induction motor", Electric Power Systems Research, Vol. 26, 1993, 155-161.

[2] Bimal K. Bose. Modern Power Electronics and AC Drives, Prentice Hall, 2007.

[3] Boukhelifa, A. Kherbouch, M. Cheriti, A. Ibtiouen, R. Touhami, O. Tahmi, R. Stator current minimization by field optimization in induction machine, International Conference on Electrical, Electronic and Computer Engineering, ICEEC'04, 2004.

[4] Chapman,P.L,Sudhoff, S.D.and Whitcomb,C.A.. Optimal current control strategies for surface-mounted permanent-magnet synchronous machine drives, IEEE Trans. Energy Convers., vol. 14, no. 4, 1999, 1043-1050.

[5] Faiz, J., and Sharifian, M.B.B. "Optimal design of three-phase Induction Motors and their comparison with a typical industrial motor," Computers and Electrical Engineering, vol. 27, 2001, 133-144

[6] Feng-Chien Lin, Shing-Ming Yang. On-Line Tuning of Efficiency-Optimized Vector Controlled Induction Motors Drives, Tamkang Journal of Science and Engineering, Vol. 6, No. 2, 2003.

[7] Gen, M. and R. Cheng, R. Genetic Algorithms and Engineering Optimization, Wiley, New York, 2000.

[8] Gnacinski, P. "Energy saving work of frequency controlled induction cage machine," Energy Conversion and Management, Vol. 48, 2007, 919-926.

[9] Goldberg, D.E. Genetic Algorithms in Search, Optimization and Machine Learning, Addison Wesley, New York, 1989.

[10] Jazdzynski, W. "Multicriterial optimization of squirrel-cage induction motor design," IEE Proceedings, vol. 136, Part B, no.6, 1989.

[11] Krishnan, R. Electric motor drives- Modeling, Analysis, and Control, Prentice Hall of India Publication,2003.

[12] Lähteenmäki, J.K. Optimization of high-speed motors using a genetic algorithm, EMD97, IEE,1997.

[13] Lim, S.and Nam, K. Loss-Minimizing Control Scheme for Induction Motors, IEEE Proc. - Electr. Power Appl., Vol.151, No. 4, 2004.

[14] Minh Ta-Cao and Yoichi Hori. Convergence Improvement of Efficiency Optimization Control of Induction Motor Drive, Industrial Applications Conference, Conference record of IEEE, Vol. 3, 2000, 1662-1669.
[15] Muravlev, O.,Muravleva, O. and Vekhter, E. "Energetic parameters of induction Motors as the basis of energy saving in a variable speed drive," Electrical Power Quality and Utilization, Vol.IX, No. 2, 2005.

[16] Palit, B.B. Energy saving operation at induction motors by voltage reduction at no-and low partial load, in Proc. IEEE Ind. Appl. Annual Meeting, 1989, 147-151.

[17] Paul C. Krause, O.Wasynczuk, and S.D.Sudhoff. Analysis of Electric Machinery and Drive Systems. IEEE Press Series on Power Engineering, John Wiley and Sons Inc. Publication, 2004.

[18] Rasmus, K. Ursem. Models for evolutionary Algorithms and Their Applications in System Identification and Control Optimization, BRICS, 2003.

[19] Rateb H. Issa. Energy Saving in Electric Elevators with Random Loading Diagram, Journal of Engineering Studies \& Research, Baghdad, Vol.4, No.2, 1997.

[20] Rateb Issa. The Effect of Non- Nominal Voltage on Indices of AC Drive Systems, Journal of Engineering Studies \& Research, Baghdad, Vol.2, No.1, 1997.

[21] Rateb Issa, and Hussein Sarhan. Improving Mechanical Characteristics of Inverter- Induction Motor Drive System. American Journal of Applied Sciences, Vol.3, No.8, 2006.

[22] Rateb Issa, Hussein Sarhan and Ijreid Khawaldeh. Modeling and Simulation of Flux- Optimized Induction Motor, Research Journal of Applied Sciences, Engineering and Technology, Vol.2, No.6, 2010.

[23] Sandhu, K. S. and Vivek Pahwa. Simulation Study of ThreePhase Induction Motor with Variations in Moment of Inertia, ARPN Journal of Engineering and Applied Sciences Vol. 4, No. 6, 2009.

[24] Sundareswaran, K. and Palani, S. Fuzzy logic approach for energy efficient voltage controlled induction motor drive, IEEE Power Electronics and Drives Conf. Proc. PEDS 1999, $552-554$

[25] Thanga Raj, C., Srivastava, S. P. and Pramod Agarwal. Energy Efficient Control of Three-Phase Induction Motor - A Review, International Journal of Computer and Electrical Engineering, Vol. 1, No. 1, 2009. 